\title{
MEDIAÇÃO TRANSFORMATIVA NO DIREITO DE FAMÍLIA: TRATANDO A LIDE SOCIOLÓGICA
}

Djamere de Sousa Braga Leite ${ }^{1}$

\section{RESUMO}

O presente artigo discorre sobre a mediação transformativa como instrumento hábil para lidar com os litígios provenientes do Direito de Família. O objetivo desse meio autocompositivo não está no cerne do acordo, mas no fortalecimento dos elos relacionais familiares. O conflito na perspectiva da mediação transformativa é visto como uma oportunidade para compreenderse a lide sociológica envolvida na querela jurídica. A mediação transformativa constitui-se como meio pacífico de resolução de conflitos e visa à pacificação dos litígios que envolvem sujeitos que possuem relação continuada - o que não se alcança mantendo-se a intervenção no nível da construção de acordos jurídicos.

Palavras-chave: Mediação Transformativa; Família; Lide sociológica; Conflito; Diálogo.

\section{TRANSFORMATIVE MEDIATION IN THE LAW OF FAMILY: CONSIDERING THE SOCIOLOGICAL LITIGATION}

\begin{abstract}
This article discusses transformative mediation as a useful tool to deal with litigation arising from Law of Family. The purpose of this self-composite medium is not at the heart of the agreement, but rather in strengthening family relational links. In the perspective of transformative mediation, conflicts are opportunities to understand the subjacent interests in the juridical dispute (the sociological litigation). The transformative mediation arises as a peaceful mean to conflict's resolution and aims to pacify litigation involving subjects who have a continuous relationship, overcoming the restricted approach that focuses only in stablishing juridical agreements.
\end{abstract}

Keywords: Transformative Mediation; Family; Sociological; Litigation; Conflict; Dialogue.

\section{INTRODUÇÃO}

A família deve ser o locus das relações saudáveis e do exercício da solidariedade e amor mútuos. Contudo, é no seio familiar onde ocorrem os conflitos mais complexos, que deixam marcas por vezes definitivas nos sujeitos envolvidos.

\footnotetext{
${ }^{1}$ Mestranda em Direitos Humanos, Políticas Públicas e Cidadania, pela UFPB (Universidade Federal da Paraíba), bolsista Capes. Graduada em Serviço Social pela Universidade Federal da Paraíba. Bacharel em Direito pelo Instituto de Educação Superior da Paraíba. Membro da Comissão de Mediação e Arbitragem da Ordem dos Advogados do Brasil Seccional da Paraíba. Advogada.
} 
A diversidade que perpassa os contextos sociais e a cultura da intolerância, com posições antagônicas, é refletida no interior das famílias. Eventualmente, a dificuldade em lidar com tal diversidade provoca desarmonização das relações, que se polarizam e cristalizam, inibindo o diálogo no seio familiar. Isso acarreta cisões nas relações, ao ponto de necessitar-se de um terceiro que decida o futuro, de forma fria e pautado em lei.

Ora, os limites dos magistrados nas lides familiares são enormes: não há tempo para compreender o conflito em si, nem muito menos para tratar da lide sociológica que o envolve, fazendo tal fato com que os litígios no Direito de Família se tornem circulares e recorrentes.

É nesse prospecto que trazemos a Mediação Transformativa como meio mais adequado para pacificação das relações familiares, uma vez que difere da mera conciliação: esta última tem o condão acordista, focando apenas no problema pontual, sem, contudo, pacificar ou fortalecer as relações dos sujeitos envolvidos nesse tipo de litígio.

A Lei de Mediação e o Código de Processo Civil dirimem essas diferenciações entre a conciliação e a mediação, geralmente confundidas no meio jurídico. A Lei 13.140 de 26 de junho de 2015, conhecida como a Lei de Mediação, no parágrafo único, do artigo primeiro, considera a mediação como uma atividade técnica exercida por um terceiro imparcial que, escolhido ou aceito pelas partes, as auxilia e estimula a identificarem ou desenvolverem soluções consensuais para a controvérsia. Conceber uma justiça que permite às partes a oportunidade de decidirem a melhor solução para o litígio é um grande avanço do Poder Judiciário no Brasil.

Contudo, a Lei 13.105 de 16 de março de 2015, ou seja, o Código de Processo Civil, estabelece diferenças entre as atuações dos mediadores e conciliadores; no art. 165, os parágrafos segundo e terceiro, respectivamente, preceituam que os conciliadores atuarão preferencialmente em casos nos quais não haja vínculo anterior entre as partes, auxiliando-as a compreenderem as questões e os interesses em conflito, de modo que elas possam, pelo restabelecimento da comunicação, identificar, por si próprias, soluções consensuais que gerem benefícios mútuos.

O objetivo do trabalho ora apresentado é apontar a Mediação Transformativa como a mais adequada aos litígios que envolvem o direito de família, pois entende o conflito como uma oportunidade para o crescimento e entendimento das relações: essa estratégia de intervenção não tem por finalidade o sucesso do acordo, mas sim proporcionar às partes a oportunidade de dialogarem e ajudá-las a compreenderem por que chegaram ao litígio. Desse 
modo, a mediação transformativa também tenta alcançar a parte submersa do conflito ${ }^{2}$, ou seja, o que não está na exordial. Como se antecipou, muitos dos interesses subentendidos em conflitos jurídicos dizem respeito a variáveis psicossociológicas que, não ditas, interferem decisivamente para impasses ou o renascimento contínuo de lides processuais: tais variáveis são as chamadas lides sociológicas ${ }^{3}$ (BACELLAR, 2003; AZEVEDO, 2009).

Como o próprio nome revela, a mediação transformativa tem a função de transformar as relações, através do diálogo construtivo, pacificando as mesmas ou, senão, as tornando mais negociáveis. Por essa característica, ela se presta para o manejo da já referida lide sociológica, que muitas vezes se faz presente em litígios judiciais de cunho familiar: além dos fatos expostos nas exordiais, as posições trazem para o subsolo das disputas jurídicas interesses não declarados, conscientes ou não, que tomam o caminho institucional para prevalecerem. Assim, em processos sobre a guarda de menores, por exemplo, a intransigência pode revelar desejos de vingança e punição do ex-cônjuge que se sente vilipendiado.

A mediação transformativa, então, visa tratar as posições e interesses, de forma dialógica, pacífica e consensual. Corroborando nosso entendimento, Warat (2001) destaca ser a mediação uma proposta transformadora do conflito, pois não se preocupa com o litígio ou com a verdade formal contida nos autos, nem tampouco tem como única finalidade o acordo. Desse modo, podemos afirmar que essa modalidade de mediação foca no restabelecimento do processo de comunicação entre as partes - quiçá mesmo de cada parte consigo mesma, já que

\footnotetext{
2 "No mundo do Direito o conflito é visto, num primeiro olhar, como um fenômeno jurídico e é trabalhado como lide, com os paradigmas da adversidade. No campo da autocomposição vamos trabalhar o conflito do ponto de vista da complexidade, numa perspectiva interdisciplinar, com construções conjuntas de significados, através do conhecimento de várias áreas, para ligar ideias, aprofundar as percepções, focalizar a atenção colaborativa e criar um movimento para frente. Nos processos autocompositivos é possível ir mais fundo na análise do conflito e ele precisa ser visto com toda complexidade intrínseca à vida humana e social, com intenção interdisciplinar, a exigir a interconexão de saberes e análises referentes à identificação as emoções e da razão; do passado, presente e futuro, dos sentimentos e necessidades, entre outros" (NUNES, 2016, p.129).

3 "Um conflito possui um escopo muito mais amplo do que simplesmente as questões juridicamente tuteladas sobre a qual as partes estão discutindo em juízo. Distingue-se, portanto, aquilo que é trazido pelas partes ao conhecimento do Poder Judiciário daquilo que efetivamente é interesse das partes. Lide processual é, em síntese, a descrição do conflito segundo os informes da petição inicial e da contestação apresentados em juízo. Analisando apenas os limites dela, na maioria das vezes não há satisfação dos verdadeiros interesses do jurisdicionado. Em outras palavras, pode-se dizer que somente a resolução integral do conflito (lide sociológica) conduz à pacificação social; não basta resolver a lide processual - aquilo que foi trazido pelos advogados ao processo - se os verdadeiros interesses que motivaram as partes a litigar não forem identificados e resolvidos). Além do problema imediato que se apresenta, há outros fatores que pautam um conflito, tais como o relacionamento anterior das partes, as suas necessidades e interesses, o tipo de personalidade das partes envolvidas no conflito, os valores das partes e a forma como elas se comunicam. Muitos desses fatores considerados secundários por alguns operadores do direito estão, na verdade, na origem do conflito e, por isso, devem ser levados em conta na solução do problema. A mediação deve considerar aspectos emocionais durante o processo e ao mediador não caberá decidir pelas partes, mas conduzi-las a um diálogo produtivo, superando barreiras de comunicação a fim de que as partes encontrem a solução" (AZEVEDO, 2016, p.240).
} 
a sinceridade para com outrem presume a sinceridade consigo mesmo. Favorecer a comunicação e exercitar a sinceridade, pressupondo o refazimento da relação com o outro como uma necessidade são, portanto, características distintivas da mediação transformativa.

Neste artigo, utilizamos, como metodologia, a pesquisa teórica, por meio de revisão bibliográfica de livros e artigos científicos sobre o tema. Inicialmente, tratamos do conflito e de seu papel implícito nas disputas jurídicas - o que vem a ser a lide sociológica, em síntese. No segundo momento, discorremos acerca do papel do Mediador Familiar. Em seguida a Mediação Transformativa como a melhor forma autocompositiva para tratar os conflitos. Por fim, nas considerações finais, demonstraremos que em se tratando de lides familiares, a autocomposição de cunho transformativo, elabora processos dialógicos capazes de gerar pacificação e fortalecimento das relações.

\section{O CONFLITO E A LIDE SOCIOLÓGICA QUE ENVOLVE O DIREITO DE FAMÍLIA}

O conflito faz parte da vida de todo ser humano, não importa o âmbito social em que esteja inserido. Sendo as pessoas diferentes e diversos seus interesses, elas precisam conviver para o atendimento da maioria de suas necessidades, o que gera um paradoxo: buscar a proximidade em meio à constatação sobre as distâncias que caracterizam as singularidades, quando comparadas entre si.

Destarte, conviver torna-se praticamente sinônimo de lidar com conflitos. O conflito, nessa perspectiva, deixa de ser problema para tornar-se condição da humanidade e da convivência. Sempre presente, o conflito torna-se, como destaca Bobbio (1999), uma das formas de interação entre indivíduos, grupos, organizações e coletividades. Para o autor, qualquer grupo social ou sociedade histórica pode se definir, não importando sua época, de acordo com as formas de conflito e de cooperação entre os diversos atores que nela surgem.

Ora, isto significa que o conflito e sua valência moral tiveram diferentes significados ao longo da história: por muito tempo, a violência foi o meio mais frequente de resolução de conflitos. Com o advento da Modernidade, os ideais de fraternidade e igualdade concorreram para que mais e mais as civilizações ocidentais admitissem a convivência pacífica como estratégia de sobrevivência mais eficaz. 
Nem por isso, pode-se dizer que tal processo de modernização alcançou igualmente todos os âmbitos sociais. Mesmo que os discursos políticos possam ter-se afinado, por algum tempo, em torno da paz como valor desejável, na realidade microscópica diária, reconhecemse conflitos que ainda são manejados com estratégias muito próximas das disputas antigas resolvidas pela base da força física ou institucional. No caso de sociedades de direito androcêntrico, por exemplo, os conflitos familiares sempre favoreciam os homens, que foram senhores da vida e da morte de suas esposas e filhos.

Hoje em dia, felizmente, esse cenário vem se modificando. Muitos movimentos sociais - em particular o feminismo - conquistaram direitos que, não obstante as resistências culturais (particularmente aquelas de cunho religioso tradicional), penetram na cultura e transformam relações - consequentemente, também, o direito.

Portanto, os conflitos que cercam o direito de família são processos dinâmicos e em plena evolução, daí os novos moldes de parâmetros de família. Não apenas se verifica hoje o reconhecimento de famílias presididas por mulheres - como principais provedoras -, mas, igualmente, de famílias homoafetivas, de famílias compostas por relações não conjugais (em que avós e netos, por exemplo, exercem-se cuidados mútuos, decorrentes do vazio intergeracional).

Quando essas e outras formas de ser família fazem-se, com elas também podem surgir os conflitos. No caso do Direito de Família, muitas dessas novidades tornam-se problemas a serem pensados pela via da conciliação - caso não haja mais condições para repensar-se e se refazer a relação. Porém, um número ainda maior de casos beneficia-se, no âmbito judicial, quando a mediação transformativa é posta em ação, já que ela auxilia os operadores do direito e as partes envolvidas a identificarem e incluírem, no debate inerente à lide processual, variáveis individuais e grupais que, de caráter psicossociológico, são fortes o bastante para entravarem ou desfazerem obstáculos próprios aos dispositivos jurídicos para o manejo do conflito.

Por isso é possível afirmar: o conflito possui um significado para as partes envolvidas (BUSH; FOLGER, 2005), envolvendo um tripé entre o poder, o direito e a necessidade, os sujeitos almejam resultados, em que um ganha enquanto o outro perde.

Em se tratando do Direito de Família, inexiste o ganha/perde: ou ambos ganham com o conflito, ou ambos perdem, pelo simples fato de existirem no seio do conflito familiar elos inquebráveis - ou, senão, que deixam marcas indeléveis para as vidas de seus envolvidos, em 
de ordem subjetiva. Esse elemento dá conta de levarem as partes para o Poder Judiciário perspectivas submersas ao que está aparentemente escrita na exordial. Esse caráter subjetivo é o que chamamos de lide sociológica do conflito.

Litígios que envolvem divórcio, alimentos e guarda dos filhos muitas vezes tendem a ser concebidos como uma verdadeira batalha: só saberão o seu resultado ou fím quando, após alguns anos, o magistrado decidir de quem é o direito. Como não se tem sempre disponível a célebre justiça salomônica, não é possível, com uma medida rápida, evidenciar quais interesses pesam sobre os processos, que são tornados, em alguns casos, como aríetes para ferir a outra parte.

Serve como exemplo um caso em particular: uma das partes vociferava, a certa altura da audiência: "vamos ver quem tem o direito!". O direito, na situação, dizia respeito a quem ficaria com a guarda unilateral do filho, quem teria o direito de conviver mais com a criança, diante do pedido de guarda compartilhada. Tal disputa no judiciário terminou em um acordo, numa seção de conciliação, com as partes decidindo pela guarda compartilhada. Porém, o conflito até os dias de hoje é latente, mantendo-se a mãe inimiga do pai de seu filho, que até hoje luta para conviver com o infante.

A genitora, enquanto o pai da criança viajava, entrou como um processo de suprimento de consentimento paterno, alegando que havia se casado e que iria residir na França, pois seu atual esposo é francês; simplesmente sem ouvir o genitor, o magistrado consentiu a viagem, deixando-se de cumprir aquela decisão acordada na audiência de conciliação que regeu a guarda compartilhada e o direito dos genitores de criar e educar seu filho. O que, senão a lide sociológica, produziu primariamente esse novo quadro? Como as tensões entre o antigo casal não foram tratadas, o problema jurídico recrudesceu, agora com prejuízos para o convívio entre a criança e seu pai.

Casos como esse levam anos para serem resolvidos, com desgaste emocional e também econômico muitas vezes irreparável (pois, para a criança, por exemplo, o tempo não volta atrás, não sendo possível recuperar os anos longe de seu pai): eles minam a vida dos sujeitos e das famílias envolvidos. Como se viu, a partir da ilustração apresentada, uma audiência de conciliação familiar não tem o condão de trazer a pacificação do conflito familiar: ela apenas resolve um ponto levantado.

Ora, o Poder Judiciário não possui aparato suficiente para tratar a lide sociológica do conflito familiar, o juiz não é psicólogo, assistente social ou terapeuta, ele está adstrito ao que 
se pede e à lei. A lide sociológica que envolve o direito de família tem sido analisada pelo Poder Judiciário, após o Novo Código de Processo Civil e a Lei de Mediação que trazem.

Geralmente quando a decisão judicial ou acordo não é cumprido, as partes simplesmente se utilizam da violência, da ameaça e como tem ocorrido, casos de homicídio e suicídio são recorrentes entre aqueles que um dia juraram amor eterno.

A mediação transformativa, apresentada a seguir, mostra-se como a melhor forma para tratar os conflitos que envolve direito de família, pois esse tipo de mediação não tem o cunho simplesmente acordista, mas sua função precípua é o restabelecimento das relações.

\section{O MEDIADOR NO DIREITO DE FAMÍLIA}

Mediador, terceiro imparcial, facilitador: são inúmeras as denominações desse agente no Direito de Família. Six (2001, p.62) esclarece:

[...] o mediador não é um parceiro do advogado nem um doméstico de serviços rudimentares, ele é estritamente independente do advogado; ele não tem um trabalho de jurista, nem o de desbastar o terreno para o advogado e o juiz. Que um mediador que não tem poder, receba conselho de um advogado ou de um especialista, sim; que ele saiba que não é sua atribuição realizar uma regulamentação legal, é claro e evidente. Mas é necessário evitar toda confusão, é preciso agir com precisão, de modo que aqueles que se engajam em uma mediação não possuam, em momento algum, pensar que o mediador e o advogado, ou o mediador e o juiz, sejam parceiros em conivência, parceiros que encontrariam a vítima.

O mediador deve atuar com independência; com efeito, o artigo 166 do Código de Processo Civil elenca os princípios da mediação, dentre eles o da independência, que fornece ao mediador agir sem pressões e com liberdade, dentro da legalidade e ética que lhe são devidos (NUNES, 2016).

É corriqueiro nos Tribunais pátrios os juízes e advogados exercendo o papel de mediador familiar; isso não está proibido em lei, porém "trata-se aqui de uma questão deontológica: o mediador que é jurista ou psicólogo, por exemplo, não tem de exibir no decorrer da mediação familiar seu boné de jurista ou de psicólogo e se impor como tal" (SIX,2001, p.68). Cremos como o autor que, uma vez estabelecidos os marcos iniciais da 
mediação, evidenciando a hierarquização, faz-se com que outros princípios - como imparcialidade e autonomia da vontade das partes fiquem comprometidos, pois a posição do mediador é o de facilitador. A nosso ver, nos processos dialógicos, desenvolver-se com uma postura que se assemelhe à neutralidade, despida da sua formação profissional, será imprescindível no tratamento das lides sociológicas que envolvem conflitos dessa natureza.

Diferente do conciliador que sugere e intervém, o mediador familiar que se utiliza da mediação transformativa se apoia num tripé mais denso, em que são necessárias habilidades bem próprias desse modelo de mediação, como a verificação, o espelhamento e o resumo (VASCONCELOS, 2015), recorrendo, por exemplo, a perguntas reformuladas com conotação positiva para que o mediando se situe e encontre a melhor solução no processo.

Um caso de família atípico foi trazido ao escritório de advogados, e após análises, tomaram a decisão de não indicar a judicialização: o melhor a ser feito seria conversar, mediar o conflito ${ }^{4}$. Foi-me incumbida a missão de trazer as partes para uma conversa: após entrar em contato pelo telefone, pai e filha, desejavam conversar. Então, percebemos a carga emocional que iria permear todo o diálogo. Marcamos um sábado pela manhã e utilizamos as técnicas da mediação transformativa: após duas horas de diálogo, ambos compreenderam que a necessidade e interesse (lide sociológica) de cada um deveriam ser levados em conta. Naquele momento não houve acordo, todo o processo se desenvolveu sob o manto da informalidade, porém a questão de levar ao Poder Judiciário foi extinta.

No final de um processo judicial no Direito de Família, produz-se uma sentença, mas também uma ruptura profunda e por vezes permanente, quando não se leva em conta a lide sociológica que o envolve. O papel do mediador é imprescindível e fornecer-lhe tempo para exercer sua função traz, ao final, resultados bem construídos pelas próprias partes. Conheço bons mediadores judiciais, após algumas trocas de experiências, alguns relatam o pouco tempo para mediar; chegaram até nós muitos comentários como: "não dá para fazer mediação, apenas conciliação, são vinte minutos, não tem como!”. Certa vez, um mediador, aflito, nos confessou: "estava desenvolvendo a mediação transformativa num caso de família delicadíssimo, vi a condição das partes em encontrarem uma melhor solução, simplesmente o juiz bateu a porta da sala e disse: isso não vai acabar hoje, não? Nada respondi, levei mais um

\footnotetext{
${ }^{4}$ Importante esclarecer que numa sessão "formal” de mediação judicial, não poderia mediar tal conflito, uma vez que uma das partes buscou ajuda no escritório em que a primeira autora deste artigo estava associada. $\mathrm{O}$ uso da técnica da mediação transformativa ajudou as partes a compreenderem seus direitos e responsabilidades, assim como também a necessidade do respeito e amor mútuo entre pai e filha.
} 
tempo com a mediação e ao final, as partes haviam encontrado a melhor solução. $\mathrm{O}$ magistrado entendeu que a pressa não faz parte da mediação”.

Muitas vezes o mediador judicial necessitará conquistar o espaço, a pressa que o Poder Judiciário requer, ou melhor a celeridade, não combina com o processo da Mediação Transformativa; daí o porquê de ela ser tão pouco usada no meio judicial, leva tempo, paciência e amor à causa, uma vez que os mediadores não são remunerados. Na sua maioria os Tribunais utilizam-se do técnico judiciário, do analista ou, como na maioria dos casos, graduados com dois anos de experiência profissional, que fazem parte dos Centros Judiciais de Solução de Conflitos e Cidadania (CEJUSC).

O mediador que atua em Direito de Família e se utiliza da Mediação Transformativa, seja o conflito judicializado ou não, deve possuir habilidades: além da mera capacitação profissional, como um verdadeiro vocacionado, atua numa perspectiva transcendental, com o intuito de pacificar, unir, religar e fortalecer as relações. Fomenta uma contracultura, a da paz e a do não litígio, é como um veleiro que rema contra a maré em dias de ventos contrários.

Pode-se pensar, com efeito, que a maioria dos que se tornam excelentes mediadores familiares não são primeiramente os familiarizados com o direito ou a psicologia, mas os do "dia-dia", se assim se pode dizer, homens e mulheres da vida de todos os dias, não especialistas, pessoas da labuta quotidiana; um dos melhores mediadores familiares que se formaram no Instituto de Formação em Mediação não era: um lavrador? (SIX, 2002, p.68)

\section{A MEDIAÇÃO TRANSFORMATIVA NO DIREITO DE FAMÍLIA}

O modelo transformativo de Bush e Folger (2005) evidencia a importância de valorizar o outro e reconhecê-lo, mesmo diante das suas diferenças e posições no litígio pontual.

Sem reconhecimento não existe convívio social, ao menos duradouro e pacífico (RICOEUR apud ALVAREZ, 2012). Lides em Direito de Família são encaradas com alto grau de polarização e cristalização das posições trazidas na peça vestibular judicial, sentimento de vingança e destruição do outro permeiam todo o processo.

A insegurança, diante do Judiciário e o medo do que acontecerá impede o diálogo das partes e as chances para gerar a empatia e o espelhamento ${ }^{5}$ com o mediador. É preciso

\footnotetext{
5 “O espelhamento ocorre quando o mediador olha nos olhos e fala de volta ao mediando que ele acaba de dizer, usando palavras próximas do que ele expressou. O bom espelhamento capta o tom das palavras quando do
} 
entender que o conflito de família é carregado de sentimentos profundos, por vezes extremamente negativos. Oliveira et al. (2008) esclarecem:

Quanto menos seguras as pessoas se sentem, menos alternativas encontram para lidar com os seus conflitos. Em um processo de conflito interpessoal, é possível desenvolver e adquirir as condições necessárias para aprimorar as relações sociais, o que fundamenta a proposta transformadora da prática da mediação. A compreensão e prática das noções de alteridade, cooperação, solidariedade e reparação auxiliam na administração pessoal dos conflitos. A isso se denomina elaboração do conflito interpessoal.

Discorrer sobre a mediação transformativa ${ }^{6}$, no direito de família, também "denominada de mediação familiar, mediação das relações familiares, mediação em sistemas familiares ou mediação em re-vinculação" (MARODIN apud CÁRDENAS 2006, p.55), é conceber a interdisciplinaridade e a transdisciplinaridade ${ }^{7}$ neste espaço, entendendo que o mediador familiar ${ }^{8}$, deverá ser aquele que possui a habilidade como a escuta ativa e empatia das partes envolvidas no conflito.

Na mediação transformativa familiar interdisciplinar ocorre um intercâmbio mútuo e interação de vários conhecimentos, com a Psicologia, o Direito, as Ciências Sociais e o Serviço Social. Para Oliveira et al. (2008), "o papel da transdisciplinaridade é constituir um conhecimento em rede que permita a integração de diferentes paradigmas para atender necessidades diversas".

O Código de Processo Civil, na parte Especial, Título III, do Livro I, aborda as regras de como devem ser tratados os conflitos nas Ações de Família, evidenciando a necessidade de uma equipe interdisciplinar, especificamente o artigo 694:

emocional do mediando que acaba de falar, com o máximo de naturalidade. A frase espelhada pode iniciar do seguinte modo: 'Então, para você, o que está acontecendo é que... '”. (VASCONCELOS, 2015, p.191).

6 "Define a mediação transformativa como sendo um método/processo coevolutivo de afirmação e transformação, com a elaboração de mediador, sem hierarquia, da apropriação à integração, recursivamente, para viabilizar o reconhecimento das diferenças, a identificação dos interesses e necessidades comuns, opções, dados da realidade e o entendimento. A mediação transformativa pode constituir a oportunidade de romper padrões relacionais e transformar a natureza destrutiva daquele determinado conflito [...] a mediação opera uma ética de alteridade, enquanto acolhimento da diferença que o outro é na relação e no mundo da vida" .(VASCONCELOS, 2015, p.190).

7 "As várias disciplinas que envolvem a mediação, a multidisciplinaridade, como o Direito, a Filosofia, a Psicologia, a Comunicação, a Complexidade, a Teoria dos Jogos, a Ética, entre outras precisam de intensa intercomunicação entre elas, a interdisciplinaridade, para gerar a sinergia e o enriquecimento recíproco na atuação do mediador. Essa abordagem transversal, esse cruzamento entre os saberes, gera a transdisciplinaridade”.( NUNES, 2016,p.130).

8 “" [...] os mediadores precisam procurar conexões. Os eventos na disputa devem ser vistos como parte de algum padrão maior. [..], o argumento de um mediando é parte de um episódio; é parte de uma série de interações que, juntas definem o self da relação, produto inacabado de muitos padrões”. (VASCONCELOS, 2015, p.190). 
Art. 694. Nas ações de família, todos os esforços serão empreendidos para a solução consensual da controvérsia, devendo o juiz dispor do auxílio de profissionais de outras áreas de conhecimento para a mediacão e conciliação.

Parágrafo único. A requerimento das partes, o juiz pode determinar a suspensão do processo enquanto os litigantes se submetem a mediação extrajudicial ou a atendimento multidisciplinar. (Grifamos)

A Lei esclarece a necessidade de os magistrados disporem de auxílio de outros profissionais, demonstrado o caráter inter, multi e transdisciplinar que envolve a mediação para os conflitos de família.

Dentre os princípios basilares da mediação o da confiança se autorrevela o mais importante: daí por que não importam a graduação ou titulações, o mediador deve ser aquele que escuta ativamente (com extrema atenção), que não sugere a solução, mas que conduz os mediandos a se posicionarem e dialogar respeitosamente, encontrando assim o melhor caminho de solução do dissenso. Até por que numa sessão de mediação, o que diz respeito ao Direito não é relevante, a questão do restabelecimento das relações saudáveis é o que importa.

A comunicação construtiva, ou seja, esse resgate do diálogo no seio familiar demonstra mudanças significativas no clima das relações. Daí por que o processo de mediação requer uma atitude de acolhimento, elaborar perguntas sem julgamento, informar sobre as regras de comunicação. A prioridade não está apenas na resolução do impasse, mas na questão relacional que requer validação dos sentimentos e habilidades para reformular mensagens que soam ofensivas.

A proposta dialógica da mediação transformativa é bem explicada por Alvarez (2012), quando expõe sobre o ser humano como centro de referência do reconhecimento, evidenciando a sua capacidade em dialogar com o outro. Essa perspectiva dialogal, segundo o autor "revela um sujeito que necessita do outro para constituir-se. Por outro lado, o projeto da vida boa só pode ser efetivado se é com e para os outros" (p.5).

Partes de um processo judicial que no passado mantiveram laços possuem uma trajetória histórica, por vezes com momentos felizes e sentimentos mútuos de expressiva solidariedade, fraternidade e amor. Contudo os conflitos que permeiam as relações humanas no seio familiar são geralmente constantes e desgastantes. A perspectiva dialógica perde-se, na verdade a capacidade de conversar dá lugar ao silêncio ou a palavras agressivas que geram violência. 
Casais que perderam a sua habilidade de conversar possuem apenas o vínculo judiciário para se digladiarem, não conseguem separar os conflitos conviviais dos de parentalidade. Trazem os males da convivência desgastada para o judiciário e não entendem que, no tocante à parentela, há direitos e deveres que devem ser cumpridos. Usam o litígio judicial como uma forma de disputa, de batalha em que o outro deve perder.

Muitas vezes a relação opressora entre os casais faz com que a única forma do oprimido expor sua opinião, ideia ou direito, seja na frente do juiz ou do mediador.

Por essas razões, faz-se necessário observar os fundamentos e requisitos para que a mediação transformativa se torne uma fonte perene de diálogo e fortalecimento dos elos relacionais. Vasconcelos (2015) elabora sinteticamente os requisitos que devem ser observados no processo de mediação:

a) atitude de acolhimento, tolerância e entendimento das diferenças "com seu ethos de alteridade e amor" (p.153);

b) escuta ativa, é a comunicação que permite que o outro se expresse sem que seja julgado, é uma escuta com atenção, afago;

c) perguntas sem julgamento, não é permitido aconselhar na mediação, é razoável ao mediador através das perguntas, levar o mediando a encontrar a melhor solução;

d) reciprocidade escuta-fala, os mediandos são orientados a escutar enquanto o outro fala, sem interrupções;

e) prioridade da questão relacional, que se auto explica, pois na mediação, quando há questões materiais, deve-se dar prioridade as relações;

f) validação dos sentimentos com empatia, é o mesmo que colocar-se no lugar do outro, de forma equânime entre as partes;

g) reformulação de mensagens ofensivas, o mediador deve ter a habilidade de repetir a mensagem negativa, com conotação positiva.

É preciso, porém, evidenciar que o êxito da mediação não está adstrito ao "bom acordo", mas está ligado ao fato de que ao dialogar, as partes encontram uma alternativa em conjunto, gerando um processo de ganha-ganha. Esse método autocompositivo faz com que as partes encontrem um lugar em que se sintam ouvidas, afagadas e com seus sentimentos validados.

O processo de ganha-ganha promove uma desconstrução do conflito, no afã de promover uma restauração nas relações; 
A mediação privilegia a desconstrução do conflito (CALCATERRA, 2002) e a consequente restauração do diálogo e da convivência pacífica entre pessoas. Sabemos que a construção de acordos não garante que seja efetivamente dirimido o conflito entre as partes e, por vezes, chega a acirrálo. Todavia, a base da pacificação social reside no restauro da relação social e na desconstrução do conflito entre litigantes. A permanência do conflito possibilita a construção de novos desentendimentos ou de novos litígios; esgarça o tecido social entre as pessoas envolvidas em uma discordância e entre as redes sociais que as apoiam e das quais fazem parte. A permanência do conflito é, portanto, terreno fértil para manter latente a possibilidade de novas discórdias e o ânimo de desavença entre os grupos sociais de pertinência dos litigantes. Por dedicar-se ao restauro da relação social e à desconstrução do conflito - o que lhe confere caráter preventivo de amplo alcance social -, a mediação vem sendo considerada o método de eleição ideal ou mais apropriado para desacordos entre pessoas cuja relação vai perdurar no tempo - seja por vínculos de parentesco, trabalho, vizinhança ou parceria. (ALMEIDA, 2015, p.86).

Essa desconstrução do conflito deve ser entendida sob a ótica de encará-la positivamente, como uma forma de entender as relações e, através delas, trazer a pacificação dos litígios no Direito de Família, num entendimento mais profundo da lide sociológica que os envolvem.

A família contemporânea, permeada pela diversidade parental, elenca novos tipos de conflitos; por essa razão, "o caráter interdisciplinar é patente na mediação familiar, que se ocupa da desconstrução do conflito, assim como da preservação da relação social subjacente" (LOBO; PELAJO, 2016, p.444). No entendimento das autoras, a mediação trará a preservação da capacidade de diálogo à harmonia das famílias a serem recompostas e ao desenvolvimento emocional equilibrado.

No âmbito do judiciário, como já abordado, nas Varas de Família, é utilizada a conciliação. Contudo, VASCONCELOS (2015) discorre:

A conciliação é um modelo de mediação focada no acordo. É apropriada para lidar com relações eventuais de consumo e de outras relações causais em que não prevalece o interesse comum de manter o relacionamento, mas apenas o interesse de equacionar interesses materiais. Muito utilizada, tradicionalmente, junto ao Poder Judiciário, embora quase de modo apenas intuito como procedimento, a conciliação é mais rápida do que uma mediação transformativa, porém, muito menos eficaz.

Para o autor a mediação transformativa pode constituir a oportunidade de romper padrões relacionais e transformar a natureza destrutiva daquele determinado conflito (p.190). Os conflitos sempre envolverão posições polarizadas, sentimentos negativos e, no que concerne ao direito de família, mágoas e ressentimentos profundos. As partes não têm a 
dimensão das feridas produzidas, simplesmente por que não há mais diálogo, a lide sociológica do conflito as impede de ouvir o outro, numa produção de empatia.

A mediação transformativa não é uma fórmula mágica e de máxima eficácia que irá extinguir o conflito e trazer a paz eterna; pelo contrário, na nossa concepção através dela os sujeitos encararão o conflito sob uma ótica diferenciada, percebendo que a sua resolução pode gerar processos de novos parâmetros relacionais.

O ser humano, quando perde a capacidade de dialogar, perde também a de amar. Nunes (2016) cita Paulo Freire: "se não amo o mundo, se não amo a vida, se não amo os homens, não me é possível o diálogo". Considerando-o um dos educadores mais influentes do século XX, comenta ser para o célebre educador o diálogo a condição do modo humano de agir. Não há diálogo sem um profundo amor ao mundo e aos homens, é preciso o diálogo autêntico- reconhecimento do outro e reconhecimento de si, no outro (p.168) e assevera:

O diálogo é o componente fundante das relações sociais e o único processo que permite o aprimoramento das relações humanas; se for conduzido com cuidado leva a conversações significativas e produtivas, tornando os relacionamentos mais afetuosos e interessantes.

Tratar a lide sociológica que envolve o conflito é condição sine qua non para a pacificação, para a não reincidência processual, pois uma vez restabelecido o diálogo, criamse pontes, e novos conflitos encontrarão também novos caminhos através da prática dialógica. Dessa forma, podem os litígios que envolve o Direito de Família serem tratados adequadamente; compreendendo que a lide sociológica precisa ser trazida à lúmen, a parte submersa do conflito quando mediada na perspectiva transformativa, pacífica, gera alteridade, processos empáticos e reconhecimento.

\section{CONSIDERAÇÕES FINAIS}

A adoção das práticas autocompositivas no Poder Judiciário brasileiro é um fenômeno positivo e necessário, após alguns anos de luta por parte de alguns operadores do Direito para a implantação de um sistema multiportas, ou seja, um sistema em que o cidadão teria a oportunidade de escolher além da litigância jurídica, outro meio para resolver suas querelas, acarretou no país uma nova forma de lidar com os conflitos. 
A cultura de litígio no Brasil acarreta o alto índice de processos judiciais, são mais de cem milhões de processos em tramitação ${ }^{9}$, dentre eles, os relacionados ao Direito de Família, com mais de oitocentos mil processos: se pensarmos que um processo envolve no mínimo duas pessoas, temos mais de um milhão e meio de pessoas envolvidas nos litígios de família em nosso país.

Muitos desses processos são recorrentes, como por exemplo pedidos de exoneração de pensão alimentícia ou sua revisão, temas de direito que poderiam ser resolvidos com a mediação transformativa, uma vez que as partes teriam a oportunidade de dialogar e compreender os limites, possibilidades e necessidades uns dos outros.

O sistema jurídico tem sido palco de disputas intermináveis, famílias se digladiam com o objetivo de destruir o outro, sentimento de vingança e ódio se perpetuam, quando na verdade, a judicialização é o único meio de "diálogo" entre as famílias. Rupturas familiares ocasionam desgastes emocionais, relacionais e também econômicos.

A conciliação não consegue tratar os conflitos de relações continuada, diferentemente da mediação transformativa, que emprega o esforço em fortalecer a relação, pois, uma vez trabalhando com processos empáticos e dialógicos, atenta para a lide sociológica envolvida.

O caráter multidisciplinar, já consagrado no artigo 694 da Lei de Processo Civil, da Mediação, reforça nosso entendimento no que toca ao apoio de outros profissionais para a busca do fortalecimento das relações, uma vez que numa sessão de Mediação com escopo transformativo não importa o direito envolvido.

A Mediação transformativa como modelo focado na relação, provoca as partes a compreenderem o cerne do conflito, favorecendo o diálogo, com o fito de transcender ao ponto focal do conflito.

\footnotetext{
${ }^{9}$ Dados do CNJ - Conselho Nacional de Justiça de 2017. O Relatório Justiça em Números 2017 revelou que, no ano passado, 79,7 milhões de processos tramitaram no Judiciário do País, com 29.351.145 novas ações. Além de informações sobre a litigiosidade, produtividade e despesas, o estudo apresenta análise dos assuntos mais demandados por ramo da Justiça. Responsável por aproximadamente $67 \%$ do total de processos ingressados no Poder Judiciário, a Justiça Estadual trata de ampla gama de assuntos do cotidiano do cidadão. O tema Direito Civil aparece entre os cinco assuntos com maiores quantitativos de processos em todas as instâncias desse segmento. O destaque fica para as ações relativas a Obrigações/Espécies de Contratos (1.944.996), Responsabilidade civil/Indenização por dano moral (1.760.905) e Família/Alimentos (853.049). Enquanto no $1^{\circ}$ grau, há elevado número de ações na área de Direito Tributários/Dívida ativa (1.103.625), na segunda instância um dos destaques é o Direito Penal/Crimes previstos na legislação extravagante/crimes de tráfico ilícito e Uso indevido de drogas (256.239). Já nos juizados especiais e nas turmas recursais, o Direito do Consumidor/Responsabilidade do fornecedor/Indenização por dano moral é o assunto mais recorrente, com, pelo menos, 1.234.983 e 144.754 processos, respectivamente. Disponível na Internet via: http://www.cnj.jus.br/noticias/cnj/85421-justica-em-numeros-indica-os-assuntos-mais-demandados-em2016-nos-tribunais .(grifamos)
} 
Essa forma consensual de resolução de conflitos é a mais adequada para tratá-los, principalmente os que envolvem o direito de família, pois a dialogicidade, a pacificação, o restabelecimento e fortalecimentos das relações, são seus focos centrais, contribuindo assim para o fomento de uma cultura de paz.

\section{REFERÊNCIAS}

ALMEIDA, Tania. Mediação e Conciliação: dois paradigmas distintos, duas práticas diversas. In: SOUZA, Luciane Moessa de. Mediação de conflitos: novo paradigma de acesso à justiça. Santa Cruz do Sul : Essere nel Mondo, 2015.

ALVAREZ, Alejandro Bugallo. O Reconhecimento do outro como pressuposto e fundamento do Direitos Humanos em Paul Ricoeur. In: BENTES, Hilda Helena Soares; SALLES, Sérgio de Souza (Org.). Mediação e Educação em Direitos Humanos. Rio de Janeiro: Lumen Juris, 2012.

AZEVEDO, André Gomma (org). Manual de Mediação Judicial. Brasília: Ministério da Justiça e Programa das Nações Unidas para o desenvolvimento- PNUD,2009

BACELLAR, Roberto Portugal. Juizados Especiais: a nova mediação paraprocessual. São Paulo: Ed. Revista dos Tribunais,2003.

BOBBIO, Norberto. As ideologias e o poder em crise. 4.ed. Brasília: Editora Universidade de Brasília,1999.

BRASIL. Lei 13.140 de 26 de junho de 2015. Lei de mediação entre particulares como meio de solução de controvérsias e sobre a autocomposição de conflitos no âmbito da administração pública. http://www.planalto.gov.br/ccivil 03/ ato2015-

2018/2015/lei/L13140.htm. Acesso em 25 abr. 2018.

BRASIL. Lei 13. 105, de 16 de março de 2015. Código de Processo Civil.

http://www.planalto.gov.br/ccivil_03/_ato2015-2018/2015/lei/113105.htm. Acesso em 05 abr.2018.

BRASIL. CONSELHO NACIONAL DE JUSTIÇA. Azevedo, André Gomma de (Org.). Manual de Mediação Judicial, 6. ed.Brasília/DF:CNJ, 2016.

BUSH, Baruch, Robert A.; FOLGER, Joseph P. The promisse of mediation: the transformative approach to conflict. San Francisco: Jossay Bass, 2004.

, Robert A. Baruch; FOLGER, Joseph P. Transformative mediation: theorethical foundations. In: BUSH, Robert A. Baruch; FOLGER, Doroth J. Della (eds) Transformative 
mediation: a Soucerbook Hempstead, NY and Reston, VA: Institute for the Study of Conflitct Transformation abd The Association dor Conflict Resolution, 2010.

CÁRDENAS, Eduardo José. La Mediación em Conflitos Familiares. 2.ed. |Buenos Aires: Lumen/Hvmanitas, 1999.

LOBO, Monica; PELAJO, Samantha. Mediação Familiar: premissas emocionais e jurídicas. In: ALMEIDA, Tania; JONANTHAN, Eva; Pelajo, Samantha.(COORD.) Mediação de conflitos: para iniciantes, praticantes e docentes. Salvador: Ed. Jvspodium, 2016.

NUNES, Antônio Carlos Ozório. Manual de Mediação: Guia prático da autocomposição. São Paulo: Editora Revista dos Tribunais, 2016.

OLIVEIRA, Maria Coleta et al. Mediação familiar transdisciplinar: uma metodologia de trabalho em situação de conflito de gênero. São Paulo: Summus, 2008.

VASCONCELOS. Carlos Eduardo de. Mediação de Conflitos e práticas restaurativas. 4.ed. Rio de Janeiro: Forense; São Paulo: MÉTODO,2015.

WARAT, Luis Alberto. O ofício do mediador. Florianópolis: Habitus, 2001.

SIX, Jean François. Dinâmica da mediação. Tradução de Giselle Groeninga, Águida Arruda e Eliane Riberti. Belo Horizonte: Del Rey, 2001. 